\title{
BMJ Open Quality of life and associated factors among university students during the COVID-19 pandemic: a cross- sectional study
}

\author{
Mohammad Farris Iman Leong Bin Abdullah (D), Nor Shuhada Mansor, \\ Mohd Afifuddin Mohamad, Soo Huat Teoh
}

To cite: Leong Bin Abdullah MFI, Mansor NS, Mohamad MA, et al. Quality of life and associated factors among university students during the COVID-19 pandemic: a crosssectional study. BMJ Open 2021;11:e048446. doi:10.1136/ bmjopen-2020-048446

- Prepublication history and additional supplemental material for this paper are available online. To view these files, please visit the journal online (http://dx.doi.org/10.1136/ bmjopen-2020-048446).

Received 26 December 2020 Accepted 15 September 2021

Check for updates

(c) Author(s) (or their employer(s)) 2021. Re-use permitted under CC BY-NC. No commercial re-use. See rights and permissions. Published by BMJ.

Lifestyle Science Cluster, Advanced Medical and Dental Institute, Universiti Sains Malaysia, Kepala Batas, Malaysia

Correspondence to Dr Mohammad Farris Iman Leong Bin Abdullah; farris@usm.my

\section{ABSTRACT}

Objective This study aimed to evaluate the quality of life (QoL) and determine its association with various factors and social support among university students during the COVID-19 pandemic after the end of movement lockdown. Design, setting and participants This online crosssectional study recruited 316 participants. The inclusion criteria were students 18 years and above who were registered with the faculties of medicine at Malaysian public universities located in Klang Valley and in the states of Penang and Kelantan in Peninsular Malaysia. The exclusion criteria were those who presented with psychotic disorders, bipolar mood disorder or a history of illicit drugs.

Outcome measures Participants were administered a self-reported questionnaire to gather data on demographic, personal, clinical and psychological characteristics. The questionnaire comprised of the 21-item Depression, Anxiety and Stress Scale, the Multidimensional Scale of Perceived Social Support, and the WHO Quality of LifeBrief Version (WHOQoL-BREF).

Results The psychological and social QoL scores were lower than the non-pandemic norms of the general population, while the physical health and environmental QoL scores were comparable. After adjusting for relevant demographic, personal and clinical variables, religious coping, greater number of hours of online classes attended, and greater social support from family, friends and significant others were significantly associated with higher QoL among the participants. Frustration due to study disruption, living in areas with a high prevalence of COVID-19 cases, and a higher severity of depressive and stress symptoms were significantly associated with lower QoL.

Conclusion COVID-19 impaired the QoL of university students even after the movement lockdown was lifted.

\section{INTRODUCTION}

SARS-CoV-2 is a highly infectious and contagious virus of the coronavirus family. Since the WHO announced it a global pandemic on 11 March 2020, the COVID-19 pandemic has been a major global health hazard. ${ }^{1}$ Malaysia, which has been experiencing an alarming increase in the prevalence of COVID-19
Strengths and limitations of this study

- Data on quality of life (QoL) assessment among university students in response to the COVID-19 pandemic are lacking, particularly after the end of movement lockdowns.

- Data regarding the association between COVID19-related stressors, psychological complications (such as depression, anxiety and stress), social support and QoL among university students during the COVID-19 pandemic are also scarce.

- This online cross-sectional study filled the research gap by recruiting university students from the northern and central parts of Peninsular Malaysia to evaluate QoL and determine its association with various factors and social support after the end of the movement lockdown.

- The respondents in this study may not be representative of the university student population due to the non-probability sampling method employed.

- The cross-sectional study design did not allow the causal relationship between various factors and QoL to be determined over time.

since early March 2020, imposed a movement control order (MCO) throughout the country from March to June 2020. Under $\mathrm{MCO}$, all forms of public gatherings for social, religious, sporting or cultural purposes were banned, and all places of worship and business premises except for essential services were closed. ${ }^{2}$ The MCO was lifted in June 2020, but the rate of spread of COVID-19 in the country has not been fully under control. Fear of being infected with COVID-19 and uncertainty about the future resulting from the socioeconomic downturn and the academic disruption stemming from this global pandemic have had enormous psychological effects on university students. ${ }^{3-7}$

Quality of life (QoL) has emerged as an important measure in psychiatric research due to its frequent use as an assessment and 
treatment outcome indicator. The World Health Organization Quality of Life: Brief Version (WHOQoL-BREF) is a measurement tool that can be used to compare healthrelated QoL across many conditions and illnesses and to indicate the outcome of various QoL interventions. ${ }^{8}$ As movement lockdown and social distancing became the new norm in the daily life of university students during the height of the COVID-19 pandemic, they contributed to a significant reduction in students' activities, which is positively correlated to considerable deterioration in overall QoL. ${ }^{9}$ Hence, it is pivotal to investigate how the COVID-19 pandemic and the movement restrictions that followed affected the QoL of university students, as deterioration of QoL can contribute to diminished academic performance. ${ }^{10}$ Several factors, such as gender, education environment, years of study, depression and chronic illness, have been identified as predictors of QoL in university students. ${ }^{11}$ In Malaysia, although the MCO was lifted in June 2020, all academic activities are still restricted, all classes are still being conducted online since April 2020, and university students have not been permitted to access the university's facilities. These new norms in the academic setting in Malaysia have disrupted the usual daily routine and academic progress of university students, who are the main stakeholders of higher education. This inevitable consequence of the COVID-19 pandemic may have had a considerable impact on university students' QoL. To the best of our knowledge, data on QoL assessment among university students in response to the COVID-19 pandemic are lacking, particularly after the end of movement lockdown. Moreover, data regarding the association between COVID-19-related stressors, psychological complications (such as depression, anxiety and stress), social support and QoL among university students during the COVID-19 pandemic are scarce. Hence, this study fills this research gap by (1) evaluating the QoL of university students and (2) assessing the association between various psychological factors, social support and QoL to identify significant predictors of QoL among university students while adjusting for demographic, personal and clinical factors during the uncertain time of the COVID-19 pandemic and after lifting the movement lockdown.

\section{METHODS}

\section{Study setting and participants}

This cross-sectional online survey was conducted from 1 July to 21 July 2020, which was 3 weeks after the Malaysian government lifted the MCO on 11 June 2020. During the data collection period, although the MCO had been lifted, the rate of spread of COVID-19 in the country has not been fully under control, with the number of cumulative COVID-19 cases at 8840 cases and the number of deaths at 123 cases at the end of the data collection period. ${ }^{12}$ The data analysed in this study were partly based on the data from a cross-sectional survey of depression, anxiety and their associated factors among university students in Malaysia during the COVID-19 pandemic. The sample size was calculated based on the following formula: $n=\left[\left(Z_{1-\alpha / 2} \times \sigma\right) / \Delta\right]^{2}$, where $n$ is the total estimated sample size; $\mathrm{Z}_{1-\alpha / 2}$ is the value representing the desired $\mathrm{CI}$ in which the confidence level selected was at $95 \%$, with a critical value of 1.96; $\sigma$ is the standard deviation $(\mathrm{SD})$, which was 18.2 based on the QoL of the general population $;^{13}$ and $\Delta$ is precision with a value of 2.5. Hence, the estimated sample size needed was 243 subjects (after considering an additional 20\% sample loss). The study participants were recruited by snowball sampling from the medical faculties of Malaysian public university students in Klang Valley in central Peninsular Malaysia and in the states of Penang and Kelantan located in the northern region of Peninsular Malaysia. The online survey was initially disseminated to medical postgraduate students, who were asked to circulate the invitation to participate in the survey to other medical postgraduate students, medical undergraduate students, postgraduate and undergraduate students in medical sciences, and other students from the medical faculties of public Malaysian universities located in the targeted regions. We selected participants with a diverse range of demographic characteristics according to age, gender and marital status. Those who were 18 years and above and were registered as students at the faculties of medicine of the Malaysian public universities located in Klang Valley and the states of Penang and Kelantan in Peninsular Malaysia were eligible to participate. Those who presented with psychotic disorders, bipolar mood disorder or a history of illicit drug use were excluded from the study because these illnesses may lead to impaired mental capacity to answer the questionnaires, since people with these illnesses may present with psychotic symptoms, manic features and cognitive deficit. All participants provided informed consent and were assured of anonymity and data confidentiality. They completed the questionnaires through an online survey platform (Google Forms). A total of 381 participants responded to the online survey. We excluded 65 participants who took less than $60 \%$ of the median time to complete the questionnaires in this study (median time $=15 \mathrm{~min}$ ) to avoid any response bias. Double responses from the same participant were prevented by activating the 'limiting responses to once per person' function in Google Forms. The final sample size was 316 participants.

\section{Data collection}

A self-report questionnaire was administered to the participants to collect data on the following: demographic and personal characteristics, clinical factors, and COVID-19related stressors and coping mechanisms of participants. The coding of the responses to the demographic and personal characteristics, clinical factors, and COVID19-related stressors and coping is presented in online supplemental file 1 . The self-reported questionnaire was constructed based on previous surveys on the psychological impact of severe acute respiratory syndrome 
and Middle East respiratory syndrome epidemics on university and medical students. ${ }^{14-18}$ We included the self-reported questionnaire in online supplemental file 2. The participants were also administered the Malay version of the 21-item Depression, Anxiety and Stress Scale (DASS-21), the Malay version of the Multidimensional Scale of Perceived Social Support (MSPSS), and the Malay version of the WHOQoL-BREF. In this study, the DASS-21 subscale scores, MSPSS domain scores and WHOQOL-BREF domain scores were presented as continuous variables.

\section{Demographic characteristics}

Data on participants' demographic characteristics included age, gender, marital status and monthly living expenses. The assessment and coding of demographic characteristics are summarised in online supplemental file 1.

\section{Personal characteristics}

The personal characteristics assessed in this study were the types of courses enrolled in at the university, the level of study which the respondents were enrolled in at the university and living arrangements. The assessment and coding of personal characteristics are summarised in online supplemental file 1 .

\section{Clinical factors}

Data on two clinical factors were collected in this study: history of pre-existing medical illnesses and history of preexisting depressive and anxiety disorders. The assessment and coding of clinical factors are summarised in online supplemental file 1.

\section{COVID-19-related stressors and coping mechanisms}

Data on COVID-19-related stressors and coping mechanisms included in this study were hours of online classes attended per week, perceived prevalence of COVID-19 cases at the place of residence, frustration due to loss of daily routine, frustration due to disruption of study and use of religious coping to manage stress in response to the COVID-19 pandemic. The assessment and coding for COVID-19-related stressors and coping mechanisms are summarised in online supplemental file 1 .

\section{Depression, anxiety and stress}

Presence of depression, anxiety and stress and severity of these symptoms were evaluated with DASS-21, which is a self-report questionnaire comprising seven items per subscale; the subscales are depression, anxiety and stress. Each item was scored on a Likert scale from 0 (did not apply to me at all) to 3 (applied to me very much). The sum scores were computed by adding the scores on the items per subscale and multiplying them by a factor of 2. The sum scores for each subscale may range between 0 and 42. Hence, the total score of the DASS-21 ranges from 0 to 120. The cut-off scores for DASS-21 to define cases are 9 for the depression subscale, 7 for the anxiety subscale and 14 for the stress subscale. ${ }^{19}$ The Malay version of the DASS-21 has good Cronbach's $\alpha$ values of $0.75,0.74$ and 0.79 for the depression, anxiety and stress subscales, respectively. ${ }^{20}$

\section{Social support}

Perceived social support was measured by the MSPSS, which is a self-administered instrument that measures the perceived adequacy of social support individuals receive from friends, family and significant others/ special persons. The MSPSS has 12 items, and each item was rated on a 7-point Likert scale ranging from 1 (very strongly disagree) to 7 (very strongly agree). The cumulative score of the MSPSS ranges from 12 to 84. Each domain comprises four items, and the cumulative score for each domain ranges from 4 to 28. The higher the score, the higher the individual's level of perceived social support. The original version of the MSPSS has good internal consistency (Cronbach's $\alpha=0.88$ ). ${ }^{21}$ The Malay version of the MSPSS has been validated among Malaysian university students, showing a high internal consistency (Cronbach's $\alpha=0.94){ }^{22}$

\section{Quality of life}

The QoL of the participants was measured using the WHOQoL-BREF, which is a self-administered questionnaire used to assess QoL. It comprises 26 items: items 1 and 2 are general questions on QoL, and the other items are grouped into four domains (physical health, psychological, social relationship and environmental QoL). Each item is scored on a Likert scale ranging from 1 to 5. Each domain was scored with values from 0 to 100 , with higher scores indicating better QoL. The WHOQoL-BREF has good psychometric properties. ${ }^{23}$ The general norms for the WHOQoL-BREF domain scores are as follows: 73.5 $(\mathrm{SD}=18.1)$ for physical health QoL, $70.6(\mathrm{SD}=14.0)$ for psychological QoL, $71.5(\mathrm{SD}=18.2)$ for social relationship QoL and 75.1 (SD=13.0) for environmental QoL. ${ }^{13}$ The Malay version of the WHOQoL-BREF has demonstrated excellent psychometric properties, with an internal consistency (Cronbach's $\alpha$ ) of $0.89 .{ }^{24}$

\section{Statistical analysis}

Statistical analyses were performed using Statistical Package for Social Sciences (SPSS) V.26. Descriptive statistics were reported for participants' demographic, personal and clinical factors and COVID-19-related stressors and coping mechanisms, as well as for DASS-21, MSPSS and WHOQoL-BREF domain scores (to achieve objective 1 of the study). All categorical variables were presented as frequencies and percentages, while continuous variables were presented as mean and SD. There were no missing data.

To achieve objective 2 of the study, simple and multiple linear regression analyses were used to examine the association between COVID-19-related stressors and coping mechanisms, psychological factors, perceived social support and QoL domains. In the multiple linear regression analyses, we adjusted for relevant demographic, 
personal and clinical variables. Multicollinearity was assessed by referring to the variance inflation factor, in which all the independent variables included in the multiple linear regression models had a score of $<5$, indicating no multicollinearity. The normal probability plot of the residuals of all the multiple linear regression models demonstrated that all the points lay in a reasonably straight diagonal line from bottom left to top right, indicating that the errors of the linear regression models were normally distributed. Statistical significance was set at $\mathrm{p}<0.05$ for the multiple linear regression analyses, and all $p$ values were two-sided.

\section{Patient and public involvement}

This study was conducted without involvement of the participants, patients and the public. The findings of the study will be disseminated to the participants via email on request.

\section{RESULTS}

\section{Study participants}

All participants completed the questionnaire. The demographic, personal and clinical characteristics, and COVID-19-related stressors and coping mechanisms of the participants are summarised in table 1.

The mean physical health, psychological, social relationship and environmental QoL scores were 75.31 $(\mathrm{SD}=15.11), 67.72 \quad(\mathrm{SD}=17.14), 68.32 \quad(\mathrm{SD}=18.22)$ and 74.61 ( $\mathrm{SD}=13.68)$, respectively. The psychological characteristics, social support and QoL of the participants are presented in table 1 .

\section{Association between various factors and physical health QoL}

Table 2 illustrates the associations between COVID-19related stressors and coping mechanisms, psychological characteristics, social support and physical health QoL among the participants. Simple linear regression revealed that several factors were significantly associated with physical health QoL (table 2). However, the multiple linear regression model indicated that only three variables were significantly associated with higher physical health QoL: a greater number of hours of online classes attended per week ( $\mathrm{B}=0.287,95 \% \mathrm{CI} 0.083$ to $0.491, \mathrm{p}=0.006)$, higher family support $(\mathrm{B}=2.294,95 \%$ CI 0.848 to $3.740, \mathrm{p}=0.002)$ and higher friend support $(\mathrm{B}=2.660,95 \% \mathrm{CI} 1.216$ to $4.105, \mathrm{p}<0.001)$. In contrast, frustration due to study disruption ( $\mathrm{B}=-4.483,95 \% \mathrm{CI}-7.35$ to $-1.652, \mathrm{p}=0.002)$ and greater severity of stress symptoms $(B=-0.299,95 \%$ CI -0.601 to $-0.003, p=0.049$ ) were significantly associated with lower physical health QoL. The multiple linear regression model contributed to a significant regression equation of $F(20,295)=15.912\left(\mathrm{p}<0.001, \mathrm{R}^{2}=0.519\right)$.

Association between various factors and psychological QoL

Table 3 presents the association between COVID-19related stressors and coping mechanisms, psychological characteristics, social support and psychological QoL
Table 1 Demographic, personal and clinical characteristics, COVID-19-related stressors and coping, psychological characteristics, social support, and quality of life of participants

\begin{tabular}{|c|c|c|}
\hline Variables & $\mathbf{n}$ & $\%$ \\
\hline \multicolumn{3}{|l|}{ Demographic characteristics } \\
\hline Age & $29.51^{*}$ & $6.16+$ \\
\hline \multicolumn{3}{|l|}{ Gender } \\
\hline Male & 95 & 30 \\
\hline Female & 221 & 70 \\
\hline \multicolumn{3}{|l|}{ Marital status } \\
\hline Married & 126 & 40 \\
\hline Single/divorcee/widowed & 190 & 60 \\
\hline \multicolumn{3}{|c|}{ Living expenses spent per month } \\
\hline$\leq 3000$ Malaysian ringgit & 196 & 62 \\
\hline$>3000$ Malaysian ringgit & 120 & 38 \\
\hline \multicolumn{3}{|l|}{ Personal characteristics } \\
\hline \multicolumn{3}{|c|}{ Level of study which the respondents were enrolled in at the university } \\
\hline Undergraduate course & 138 & 44 \\
\hline Postgraduate course & 178 & 56 \\
\hline \multicolumn{3}{|c|}{ Types of course enrolled in at the university } \\
\hline Medical science-based & 69 & 22 \\
\hline Medicine-based & 247 & 78 \\
\hline \multicolumn{3}{|l|}{ Living arrangement } \\
\hline Live alone/with friends & 50 & 16 \\
\hline Live with family & 266 & 84 \\
\hline \multicolumn{3}{|l|}{ Clinical characteristics } \\
\hline \multicolumn{3}{|c|}{ History of pre-existing medical illnesses } \\
\hline No & 261 & 83 \\
\hline Yes & 55 & 17 \\
\hline \multicolumn{3}{|c|}{ History of pre-existing depressive and anxiety disorders } \\
\hline No & 301 & 95 \\
\hline Yes & 15 & 5 \\
\hline \multicolumn{3}{|c|}{ COVID-19-related stressors and coping } \\
\hline \multicolumn{3}{|c|}{ Frustration due to loss of daily routine } \\
\hline No & 177 & 56 \\
\hline Yes & 139 & 44 \\
\hline $\begin{array}{l}\text { Mean hours of online classes } \\
\text { attended per week }\end{array}$ & $5.49^{\star}$ & $3.45 \dagger$ \\
\hline \multicolumn{3}{|c|}{ Frustration due to study disruption } \\
\hline No & 107 & 34 \\
\hline Yes & 209 & 66 \\
\hline \multicolumn{3}{|c|}{ Was your place of living highly prevalent for COVID-19-positive cases? } \\
\hline No & 222 & 70 \\
\hline Yes & 94 & 30 \\
\hline \multicolumn{3}{|c|}{ Religion helped you to cope with stress during COVID-19? } \\
\hline No & 101 & 32 \\
\hline Yes & 215 & 68 \\
\hline \multicolumn{3}{|l|}{ Psychological characteristics } \\
\hline $\begin{array}{l}\text { Mean DASS- } 21 \text { depression } \\
\text { subscale score }\end{array}$ & $8.53^{\star}$ & $8.37 \dagger$ \\
\hline
\end{tabular}

Continued 


\begin{tabular}{|c|c|c|}
\hline Variables & $\mathbf{n}$ & $\%$ \\
\hline $\begin{array}{l}\text { Mean DASS-21 anxiety subscale } \\
\text { score }\end{array}$ & $6.83^{*}$ & $7.98+$ \\
\hline $\begin{array}{l}\text { Mean DASS-21 stress subscale } \\
\text { score }\end{array}$ & $10.52^{*}$ & $8.95 \dagger$ \\
\hline \multicolumn{3}{|l|}{ Social support } \\
\hline Mean family support score & $22.28^{*}$ & $4.87 \dagger$ \\
\hline Mean friend support score & $21.68^{*}$ & $4.72 \dagger$ \\
\hline $\begin{array}{l}\text { Mean significant other support } \\
\text { score }\end{array}$ & $22.07^{\star}$ & $9.16+$ \\
\hline \multicolumn{3}{|l|}{ Quality of life } \\
\hline Mean physical health QoL score & $75.31^{*}$ & $15.11 \dagger$ \\
\hline Mean psychological QoL score & $67.72^{*}$ & $17.14 \dagger$ \\
\hline Mean social QoL score & $68.32^{*}$ & $18.22 \dagger$ \\
\hline Mean environmental QoL score & $74.61^{*}$ & $13.68 \dagger$ \\
\hline
\end{tabular}

among the participants. Simple linear regression illustrated that several factors were significantly associated with psychological QoL and these are listed in table 3. The multiple linear regression model indicated that higher family support ( $\mathrm{B}=2.978,95 \%$ CI 1.633 to $4.322, \mathrm{p}<0.001$ ), higher friend support $(\mathrm{B}=2.369$, 95\% CI 1.026 to 3.712 , $\mathrm{p}=0.001)$ and higher significant other support $(\mathrm{B}=2.133$, 95\% CI 1.004 to $3.263, \mathrm{p}<0.001$ ) were significantly associated with higher psychological QoL. Only two variables were significantly associated with lower psychological QoL: the perception that the area of residence had a high prevalence of COVID-19 cases ( $\mathrm{B}=-3.112,95 \% \mathrm{CI}-5.658$ to $-0.566, \mathrm{p}=0.017)$ and greater severity of depressive symptoms $(\mathrm{B}=-0.645,95 \% \mathrm{CI}-0.898$ to $-0.393, \mathrm{p}<0.001)$. The multiple linear regression model contributed to a significant regression equation of $F(20,295)=30.897(\mathrm{p}<0.001$, $\left.\mathrm{R}^{2}=0.677\right)$.

\section{Associations between various factors and social relationship QoL}

The associations between COVID-19 stressors and coping mechanisms, psychological characteristics, social support and social relationship QoL among the participants are summarised in table 4. Simple linear regression indicated that several factors were significantly associated with social relationship QoL and these are listed in table 4. Nevertheless, the multiple linear regression model showed that only agreement that religious coping helped manage stress $(\mathrm{B}=4.013,95 \% \mathrm{CI} 0.758$ to $7.267, \mathrm{p}=0.016)$, higher family support ( $\mathrm{B}=2.091,95 \% \mathrm{CI} 0.367$ to $3.815, \mathrm{p}=0.018)$, higher friend support $(\mathrm{B}=5.304,95 \%$ CI 3.582 to 7.026 , $\mathrm{p}<0.001)$ and higher significant other support $(\mathrm{B}=2.164$, 95\% CI 0.716 to $3.612, \mathrm{p}=0.004$ ) were significantly associated with higher social relationship QoL. None of the variables predicted lower social relationship QoL. The multiple linear regression model contributed to a significant regression equation of $F(20,295)=16.624$ $\left(\mathrm{p}<0.001, \mathrm{R}^{2}=0.530\right)$.

Associations between various factors and environmental QoL The associations between COVID-19-related stressors and coping mechanisms, psychological characteristics, social support and environmental QoL among the participants are illustrated in table 5. Simple linear regression revealed that several factors were significantly associated with environmental QoL, as listed in table 5. The multiple linear regression model confirmed that agreeing that religious coping helped to manage stress $(B=3.930,95 \%$ CI 1.315 to $6.545, \mathrm{p}=0.003)$, higher family support $(\mathrm{B}=1.794$, 95\% CI 0.409 to $3.179, \mathrm{p}=0.011$ ), higher friend support $(\mathrm{B}=3.100,95 \% \mathrm{CI} 1.716$ to $4.483, \mathrm{p}<0.001)$ and higher significant other support $(\mathrm{B}=2.369,95 \% \mathrm{CI} 1.205$ to $3.532, \mathrm{p}<0.001)$ were significantly associated with higher environmental QoL. None of the variables predicted a lower environmental QoL. The multiple linear regression model contributed to a significant regression equation of $F(20,295)=12.631 \quad\left(\mathrm{p}<0.001, \mathrm{R}^{2}=0.425\right)$.

\section{DISCUSSION}

This study investigated the QoL of Malaysian university students and its association with various factors and social support when the country was still battling the COVID-19 pandemic and after the end of movement lockdown. As a comparison with the norms of the WHOQoL-BREF domain scores in the non-pandemic-affected general population, ${ }^{13}$ the psychological $\left(67.72_{\text {(study) }}\right.$ vs $70.6_{\text {(general }}$ population) $)$ and social relationship $\left(68.32_{\text {(study) }}\right.$ vs $71.5_{\text {(general }}^{\text {(general }}$ population) QoL levels reported in our study were relatively low, whereas the physical health and environmental QoL levels were comparable. This finding was not surprising because the prevalence rates of depression, anxiety and stress among the participants in this study were $36 \%$, $37 \%$ and $42 \%$, respectively, which may have led to lower psychological QoL. Furthermore, social distancing and restrictions on organising and attending social activities as preventive measures to curb the spread of COVID-19 may have contributed to lower social relationship QoL.

We found that only a greater number of hours of online classes attended per week and higher family and friend support significantly predicted an increase in physical health QoL among the participants. The literature points out that chronic absenteeism from class is associated with a higher risk of engaging in health risk behaviours, such as cigarette smoking, chronic alcohol use and risky sexual behaviours. In contrast, a sense of academic achievement is associated with a higher level of general health. ${ }^{25}{ }^{26}$ Hence, the finding that university students who attended a greater number of hours of classes had a higher physical health QoL in this study is in line with what has been described in the literature. For the relationship between family and friend support and physical health QoL, a survey of 2348 adults in the USA reported that having good friend networks and friend 
Table 2 Association between various factors and physical health quality of life

\begin{tabular}{|c|c|c|c|c|}
\hline \multirow[b]{2}{*}{ Variables } & \multicolumn{2}{|l|}{ Simple linear regression } & \multicolumn{2}{|c|}{ Multiple linear regression model $\dagger$} \\
\hline & B (95\% Cl) & $P$ value & B (95\% Cl) & $P$ value \\
\hline \multicolumn{5}{|c|}{ COVID-19-related stressors and coping } \\
\hline No & Reference & & Reference & \\
\hline Yes & $-9.166(-12.384$ to -5.949$)$ & $<0.001^{*}$ & $-2.544(-5.354$ to 0.266$)$ & 0.076 \\
\hline \multicolumn{5}{|c|}{ Frustration due to study disruption } \\
\hline No & Reference & & Reference & \\
\hline Yes & $-8.367(-11.783$ to -4.952$)$ & $<0.001^{*}$ & $-4.483(-7.315$ to -1.652$)$ & $0.002^{*}$ \\
\hline \multicolumn{5}{|c|}{ Was your place of living highly prevalent for COVID-19-positive cases? } \\
\hline No & Reference & & Reference & \\
\hline Yes & $2.910(-0.667$ to 6.488$)$ & 0.110 & $1.928(-0.803$ to 4.658$)$ & 0.166 \\
\hline \multicolumn{5}{|l|}{ Psychological characteristics } \\
\hline $\begin{array}{l}\text { Mean DASS- } 21 \text { depression } \\
\text { subscale score }\end{array}$ & $-0.997(-1.164$ to -0.830$)$ & $<0.001^{*}$ & $-0.062(-0.334$ to 0.210$)$ & 0.654 \\
\hline $\begin{array}{l}\text { Mean DASS- } 21 \text { anxiety } \\
\text { subscale score }\end{array}$ & $-0.909(-1.093$ to -0.724$)$ & $<0.001^{*}$ & $-0.254(-0.540$ to 0.031$)$ & 0.081 \\
\hline $\begin{array}{l}\text { Mean DASS- } 21 \text { stress } \\
\text { subscale score }\end{array}$ & $-0.959(-1.113$ to -0.804$)$ & $<0.001^{*}$ & $-0.299(-0.601$ to -0.003$)$ & $0.049^{*}$ \\
\hline \multicolumn{5}{|l|}{ Social support } \\
\hline Mean family support score & 6.284 (5.068 to 7.499$)$ & $<0.001^{*}$ & 2.294 (0.848 to 3.740$)$ & $0.002^{*}$ \\
\hline
\end{tabular}

*Statistical significance at $p<0.05$.

† Multiple linear regression model reported that $F(20,295)=15.912, p<0.001$, with $R^{2}=0.519$, adjusted for age, gender, marital status, living expenses, level of study which the respondents were enrolled in at the university, course enrolled in at the university, living arrangement, and history of pre-existing medical, depressive and anxiety disorders.

DASS-21, 21-Item Depression, Anxiety and Stress Scale.

support predicted increases in good subjective health status. Conversely, family and friend relationship strain may decrease long-term physical health. ${ }^{27}$ In addition, greater family and friend support is related to increased moderate-intensity and vigorous-intensity physical activity, which may enhance physical health QoL. ${ }^{28} 29$ Although our study did not assess participants' physical activity during the COVID-19 pandemic, increasing physical activity, such as exercising at home with family and friends, may help people cope with boredom and loss of daily routine, potentially enhancing physical health QoL. Our findings identified that frustration due to study disruption and higher severity of stress symptoms significantly predicted a decrease in participants' physical health QoL. Interestingly, further questioning of the participants indicated that they were complaining of uncertainty about their future as their study was prolonged, their graduation time would be delayed as a result of the COVID-19 pandemic, and that they were disturbed by loss of their daily academic routine, such as their usual classes and clinical sessions. Moreover, a switch from conventional inperson or classroom teaching to the new norm of tele-education or online classes may have disrupted the academic momentum of university students, particularly medical students in vulnerable groups, such as those with financial difficulties and students living in rural or remote areas of the country. Such students may have experienced lack of internet access, problems with internet coverage and financial constraints that forced them to take up jobs to sustain them during the trying times of COVID-19, which may have hampered their commitment to adapt to the new norm of online learning. ${ }^{30}$ The difficulties experienced by the participants were associated with increased severity of stress symptoms. High levels of stress among university students, particularly medical students, may lead to stress-related physical exhaustion, which may impair physical health QoL. ${ }^{31}$ Hence, our study findings further strengthen the link between higher severity of anxiety symptoms and lower physical health QoL. 
Table 3 Association between various factors and psychological quality of life

\begin{tabular}{|c|c|c|c|c|}
\hline \multirow[b]{2}{*}{ Variables } & \multicolumn{2}{|l|}{ Simple linear regression } & \multicolumn{2}{|c|}{ Multiple linear regression model $\dagger$} \\
\hline & B (95\% Cl) & $P$ value & B (95\% Cl) & $P$ value \\
\hline \multicolumn{5}{|c|}{ COVID-19-related stressors and coping } \\
\hline No & Reference & & Reference & \\
\hline Yes & $-9.321(-13.006$ to -5.637$)$ & $<0.001^{\star}$ & $-2.200(-4.812$ to 0.412$)$ & 0.098 \\
\hline \multicolumn{5}{|c|}{ Frustration due to study disruption } \\
\hline No & Reference & & Reference & \\
\hline Yes & $-5.814(-9.776$ to -1.852$)$ & $0.004^{*}$ & $0.362(-2.270$ to 2.994$)$ & 0.787 \\
\hline \multicolumn{5}{|c|}{ Was your place of living highly prevalent for COVID-19-positive cases? } \\
\hline No & Reference & & Reference & \\
\hline Yes & $5.212(1.180$ to 9.245$)$ & $0.011^{*}$ & $2.433(-0.105$ to 4.971$)$ & 0.060 \\
\hline \multicolumn{5}{|l|}{ Psychological characteristics } \\
\hline $\begin{array}{l}\text { Mean DASS-21 depression } \\
\text { subscale score }\end{array}$ & $-1.440(-1.601$ to -1.278$)$ & $<0.001^{\star}$ & $-0.645(-0.898$ to -0.393$)$ & $<0.001^{*}$ \\
\hline $\begin{array}{l}\text { Mean DASS- } 21 \text { anxiety } \\
\text { subscale score }\end{array}$ & $-1.119(-1.323$ to -0.916$)$ & $<0.001^{*}$ & $-0.178(-0.444$ to 0.087$)$ & 0.187 \\
\hline $\begin{array}{l}\text { Mean DASS-21 stress } \\
\text { subscale score }\end{array}$ & $-1.204(-1.369$ to -1.038$)$ & $<0.001^{*}$ & $-0.123(-0.404$ to 0.157$)$ & 0.387 \\
\hline \multicolumn{5}{|l|}{ Social support } \\
\hline Mean family support score & 9.082 (7.854 to 10.311$)$ & $<0.001^{\star}$ & 2.978 (1.633 to 4.322$)$ & $<0.001^{\star}$ \\
\hline
\end{tabular}

*Statistical significance at $p<0.05$.

† Multiple linear regression model reported that $F(20,295)=30.897, \mathrm{p}<0.001$, with $\mathrm{R}^{2}=0.677$, adjusted for age, gender, marital status, living expenses, level of study which the respondents were enrolled in at the university, course enrolled in at the university, living arrangement, and history of pre-existing medical, depressive and anxiety disorders.

DASS-21, 21-Item Depression, Anxiety and Stress Scale.

Three factors were identified as significant predictors of higher psychological QoL: higher levels of (1) family, (2) friend and (3) significant other social support. Conversely, both higher severity of depression and perception of living in an area with a high prevalence of COVID-19 cases significantly predicted lower psychological QoL. Studies on the general population and healthcare workers during the COVID-19 pandemic have pinpointed that higher social support was associated with lower anxiety and depression, whereas lower social support was associated with higher anxiety and depression. ${ }^{32-36}$ Greater family and friend support, greater integration into a social network and having a larger social network are also protective against depression. ${ }^{37}$ Higher family and friend support has also been shown to enhance psychological well-being. ${ }^{38}$ Hence, it is not surprising that higher family, friend and significant other social support for the participants in this study was associated with higher psychological QoL. Our finding that those who perceived the area in which they lived to have a high prevalence of COVID-19 cases showed reduced psychological QoL is similar to the findings of two studies in China, which reported that those living and working in close proximity to the epicentre of COVID-19 infection had higher odds of experiencing psychological symptoms such as depressive and post-traumatic stress disorder symptoms. ${ }^{36}{ }^{39}$ The tighter movement control and the fear of contracting COVID-19 (for self and family) in those who perceived that they lived in an area with a high prevalence of COVID-19 cases may have led to the emergence of higher negative affect, depreciating respondents' psychological QoL. Depression has been reported to diminish psychological QoL, which is attributed to the mood disturbance experienced by a person with depression. The degree of decrement of psychological QoL is inversely proportional to the severity of depressive symptoms. ${ }^{40}$ A study of 394 patients with depressive disorder in Ethiopia reported that the psychological QoL domain of the WHOQoLBREF score was as low as $42.8 \pm 8.20 .^{41}$ Hence, our finding of the inverse relationship between severity of depressive 
Table 4 Association between various factors and social relationship quality of life

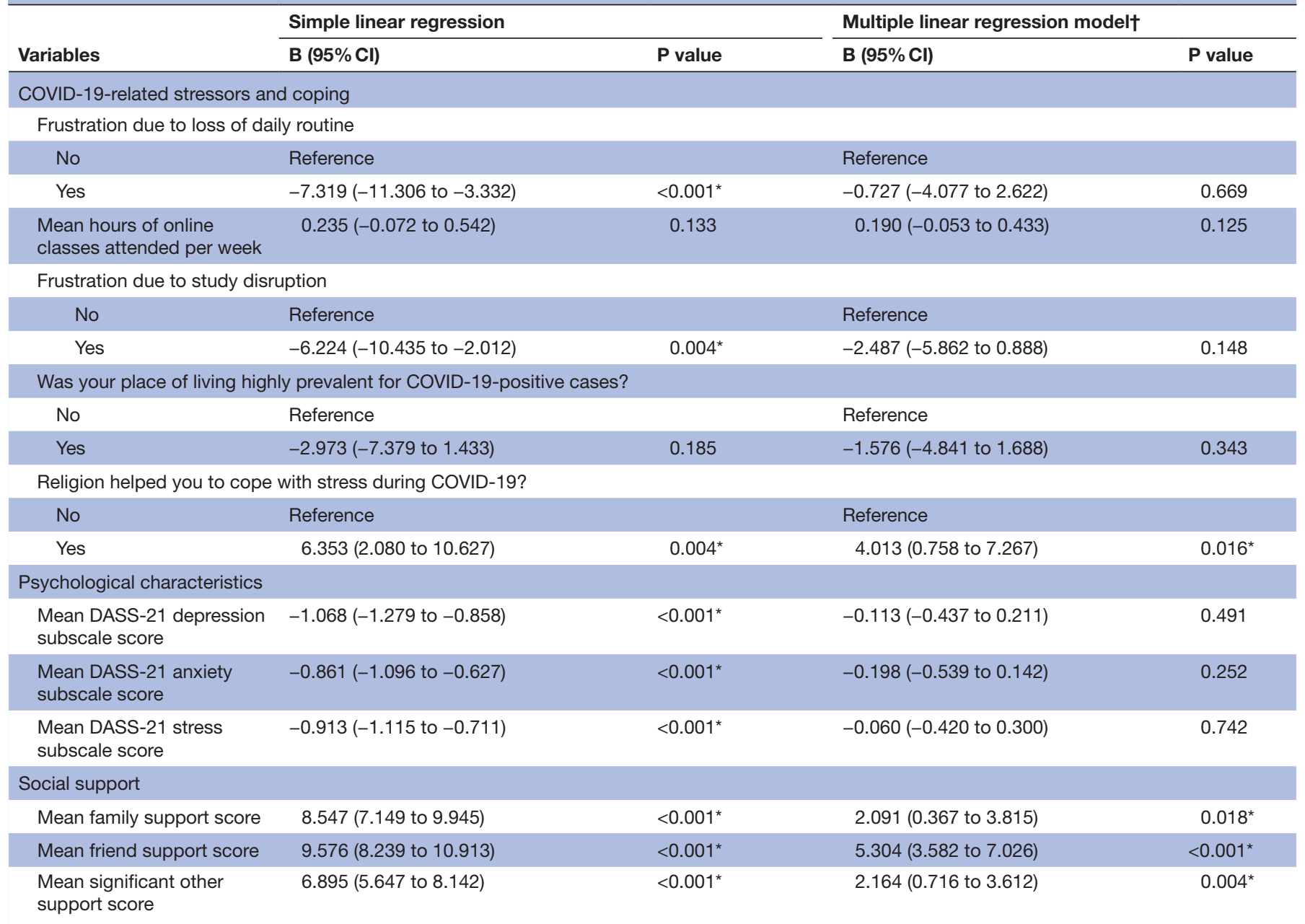

*Statistical significance at $\mathrm{p}<0.05$.

†Multiple linear regression model reported that $F(20,295)=16.624, p<0.001$, with $R^{2}=0.530$, adjusted for age, gender, marital status, living expenses, level of study which the respondents were enrolled in at the university, course enrolled in at the university, living arrangement, and history of pre-existing medical, depressive and anxiety disorders.

DASS-21, 21-Item Depression, Anxiety and Stress Scale.

symptoms and psychological QoL is well documented in the literature.

Our study indicated that using religious coping to manage stress during the COVID-19 pandemic and having higher family, friend and significant other support predicted increased social relationship QoL among the university students. No factors were significantly associated with lower social relationship QoL. Religious practices like attending religious services often increase attendees' social networks and allow frequent exchanges and sharing of information compared with attending such services less frequently. ${ }^{42}$ It has been found that persons who attend religious services with one or both parents have greater promoted feelings of well-being, and those who attend religious services with their spouses exhibit enhanced relationship commitment. ${ }^{43}$ Further questioning of the participants in our study revealed that those who attempted to cope with the MCO and COVID-19 pandemic with religious coping spent more time in prayers with family at home during the MCO; hence, they strengthened their family ties and further enhanced their social relationship QoL. These results may explain the reason behind our finding that those who used religious coping to manage stress reported better social relationship QoL. The COVID-19 pandemic has changed the quality of social relationships in that people receive better support from their family, feel more caring towards their family and others, and share their feelings with others more often. ${ }^{44}$ These shifts in social relationships support the association between higher family, friend and significant other support and greater social relationship QoL reported by the university students in this study.

The current study also highlighted that religious coping and greater family, friend and significant other support predicted an increase in environmental QoL, while none of the COVID-19-related stressors and psychological complications were associated with lower environmental QoL among university students during the COVID-19 pandemic. Similar to our study, in which most participants were Muslim, Gardner et $a l^{45}$ surveyed 114 university 
Table 5 Association between various factors and environmental quality of life

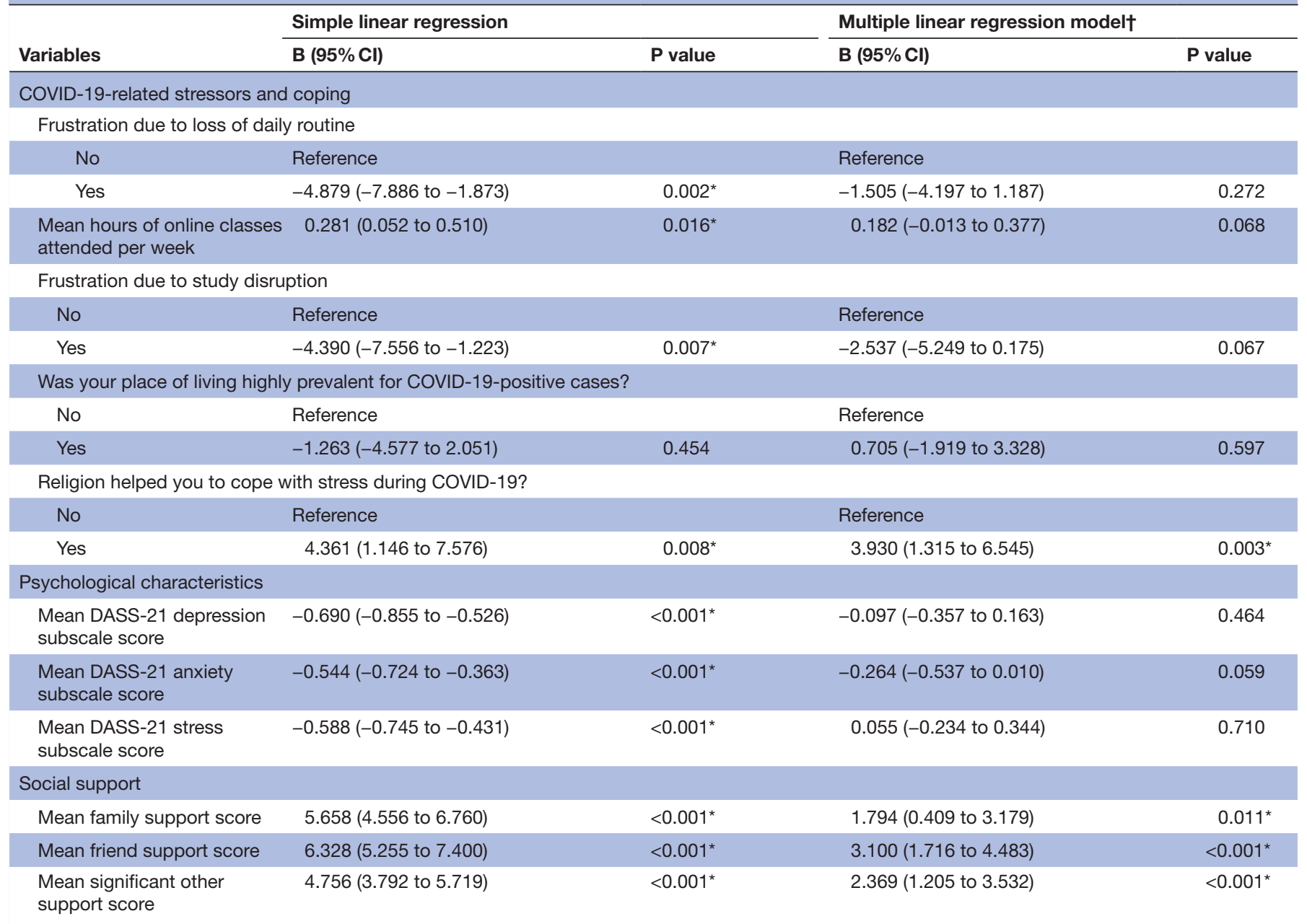

*Statistical significance at $\mathrm{p}<0.05$.

†Multiple linear regression model reported that $F(20,295)=12.631, \mathrm{p}<0.001$, with $\mathrm{R}^{2}=0.425$, adjusted for age, gender, marital status, living expenses, level of study which the respondents were enrolled in at the university, course enrolled in at the university, living arrangement, and history of pre-existing medical, depressive and anxiety disorders.

DASS-21, 21-Item Depression, Anxiety and Stress Scale.

students in New Zealand and highlighted that religious coping was positively related to QoL. Assessment of the individual domains of the WHOQoL-BREF also indicated that positive religious coping is associated with an increase in environmental QoL, ${ }^{46}$ supporting our finding that religious coping increased environmental QoL. Greater family, friend and significant other social support allows persons to strengthen their family ties, increase their social network size with friends and strengthen the positive relationship of a couple or partners. This may improve access of the person to resources and material goods, including financial support. Greater self-efficacy, competence and self-esteem as a result of good support from social networks may increase the sense of security in relation to physical surroundings and daily living, heightening environmental QoL. ${ }^{47}$ Hence, it is not surprising that greater family, friend and significant other social support leads to higher environmental QoL, as reported by this study.
Based on the findings of this study, we can highlight a few recommendations to improve the QoL of university students during the COVID-19 pandemic. First, higher education institutions (HEIs) should pay more attention to students who live in areas where COVID-19 cases are highly prevalent because these groups of students may have impaired QoL. Second, several psychological factors were reported to decrease QoL in this study, such as frustration due to study disruption and a higher severity of depressive and anxiety symptoms. During the COVID-19 pandemic, when social distancing is pivotal as an infection preventive measure, online psychosocial interventions that help curb these psychological complications are of utmost importance. Hence, HEIs should consider arranging online counselling or psychotherapy for university students needing these services. An example of an effective online psychosocial intervention for university students is the MePlusMe programme, which promotes psychological well-being, 
supports mood and daily functioning, and enhances university students' study skills. ${ }^{48}$ Third, as religious coping and family, friend and significant other social support increased the QoL of university students, HEIs and the government should focus on efforts to organise more online social support groups, encourage the use of web-conferencing applications to sustain social communication and relationships, and organise more online religious talks through HEI websites during the COVID-19 pandemic. Finally, a sufficient duration of online classes should be arranged to enhance the sense of academic satisfaction and reduce feelings of uncertainty among university students, considering that a greater number of hours of online classes attended improves the QoL of university students. However, the question of whether COVID-19-related stressors have an impact on the academic performance of university students is still unresolved. To date, few studies have investigated how COVID-19 has affected the academic performance of college students and the findings were inconsistent. ${ }^{1049}$ Despite this shortfall, several factors may be associated with better academic performance during the COVID-19 pandemic, such as better understanding of students' expectations among university instructors, feedback from students after completion of an online class, effective course design according to students' needs and higher degree of happiness among students. 5051

There are a few limitations to note in this study. First, the cross-sectional design of this study did not allow the causal relationship between various factors and QoL to be determined across time. Second, as the participants were not randomly sampled, they may not be representative of university students in Malaysia and hence this may restrict the generalisability of the findings. Third, as the questionnaires were all in the Malay language, it may have led to selection bias as international students could not participate. However, most international students in Malaysia are enrolled in private HEIs rather than in public universities. ${ }^{52}$ In addition, excluding respondents who took less than $60 \%$ of the median time of the sample to answer the online questionnaires may also lead to selection bias. Finally, we did not assess the socioeconomic background of the respondents in this study, which could be an important confounding factor. Students from lower socioeconomic backgrounds may have poor internet access and live in unfavourable living conditions, which may diminish their QoL during the COVID-19 pandemic. ${ }^{3053}$ Despite these limitations, this study fills the research gap on the scarcity of data on QoL of university students after the movement lockdown ended and has allowed several recommendations to be made.

\section{CONCLUSION}

In conclusion, this study indicated that university students had lower psychological and social relationship QoL levels in response to the COVID-19 pandemic, even after the MCO was lifted. The current study identified two COVID-19-related stressors that predicted lower QoL among university students: frustration due to study disruption and perception of living in an area with a high prevalence of COVID-19 cases. Two psychological factors were predictive of lower QoL: higher severity of depression and stress. Conversely, the greater number of hours of classes attended per week, religious coping, and higher family, friends and significant other social support were associated with higher QoL among university students. Our findings indicate the pivotal role of online mental healthcare services and social support groups, and we have made some recommendations to improve the QoL of university students during the COVID-19 pandemic.

Acknowledgements The authors would like to thank Dr Michael Wong and Dr Sarah Firdaus from Universiti Sains Malaysia for their assistance in recruiting participants and all the participants for their contribution to this research.

Contributors MFILBA: involved in the conceptualisation of research, data curation, obtained financial support, resources, investigation, methodology, data collection, data analysis and interpretation, supervision, validation, and writing of the original draft of the manuscript. NSM: involved in data curation, investigation, methodology, data analysis and interpretation, and writing and editing of a revised draft of the manuscript. SHT: involved in investigation, data collection, data analysis and interpretation, and writing and editing of a revised draft of the manuscript. MAM: involved in data collection, data analysis and interpretation, and writing and editing of a revised draft of the manuscript. All authors have reviewed and approved the final version of the manuscript before submission.

Funding This work was supported by a Short Term Grant of Universiti Sains Malaysia (grant number: 304/CIPPT/6315236).

Competing interests None declared.

Patient consent for publication Not required.

Ethics approval This study was approved by the Human Research Ethics Committee of the Universiti Sains Malaysia (reference number USM/JEPeM/ COVID19-21) and the Medical Research Committee of the Faculty of Medicine, Universiti Kebangsaan Malaysia (reference number: UKMPPI/111/8/JEP-2020-370). Each participant provided written informed consent before participating in the study.

Provenance and peer review Not commissioned; externally peer reviewed.

Data availability statement All data relevant to the study are included in the article or uploaded as supplementary information.

Supplemental material This content has been supplied by the author(s). It has not been vetted by BMJ Publishing Group Limited (BMJ) and may not have been peer-reviewed. Any opinions or recommendations discussed are solely those of the author(s) and are not endorsed by BMJ. BMJ disclaims all liability and responsibility arising from any reliance placed on the content. Where the content includes any translated material, BMJ does not warrant the accuracy and reliability of the translations (including but not limited to local regulations, clinical guidelines, terminology, drug names and drug dosages), and is not responsible for any error and/or omissions arising from translation and adaptation or otherwise.

Open access This is an open access article distributed in accordance with the Creative Commons Attribution Non Commercial (CC BY-NC 4.0) license, which permits others to distribute, remix, adapt, build upon this work non-commercially, and license their derivative works on different terms, provided the original work is properly cited, appropriate credit is given, any changes made indicated, and the use is non-commercial. See: http://creativecommons.org/licenses/by-nc/4.0/.

ORCID iD

Mohammad Farris Iman Leong Bin Abdullah http://orcid.org/0000-0002-7762-4052

\section{REFERENCES}

1 World Health Organization. WHO director-general's opening remarks at the media briefing on COVID-19 - 11 March, 2020. Available: https://www.who.int/dg/speeches/detail/who-director-general-sopening-remarks-at-the-media-briefing-on-covid-19-11-march-2020 [Accessed 19 Oct 2020]. 
2 Bunyan J. PM: Malaysia under movement control order from Wed until March 31, all shops closed except for essential services, 2020. The Malay mail. Available: https://www.malaymail.com/news/malaysia/ 2020/03/16/pm-malaysia-in-lockdown-from-wed-until-march-31-allshops-closed-except-for/1847204 [Accessed 19 Oct 2020].

3 Cao W, Fang Z, Hou G, et al. The psychological impact of the COVID-19 epidemic on college students in China. Psychiatry Res 2020;287:112934.

4 Elmer T, Mepham K, Stadtfeld C. Students under lockdown: comparisons of students' social networks and mental health before and during the COVID-19 crisis in Switzerland. PLoS One 2020;15:e0236337.

5 Li Y, Wang Y, Jiang J, et al. Psychological distress among health professional students during the COVID-19 outbreak. Psychol Med 2021:51:1952-1954.

6 Sundarasen S, Chinna K, Kamaludin K, et al. Psychological impact of COVID-19 and lockdown among university students in Malaysia: implications and policy recommendations. Int J Environ Res Public Health 2020;17:6206.

7 Zolotov Y, Reznik A, Bender S, et al. COVID-19 fear, mental health, and substance use among Israeli university students. Int $J$ Ment Health Addict 2020:1-7.

8 Guyatt GH, Feeny DH, Patrick DL. Measuring health-related quality of life. Ann Intern Med 1993;118:622-9.

9 Szczepańska A, Pietrzyka K. The COVID-19 epidemic in Poland and its influence on the quality of life of university students (young adults) in the context of restricted access to public spaces. $Z$ Gesundh Wiss 2021:1-11.

10 Grande RAN, Butcon VER, Indonto MCL, Laarni Indonto MC, et al. Quality of life of nursing internship students in Saudi Arabia during the COVID-19 pandemic: a cross-sectional study. Int J Afr Nurs Sci 2021;14:100301.

11 Solis AC, Lotufo-Neto F. Predictors of quality of life in Brazilian medical students: a systematic review and meta-analysis. Braz $J$ Psychiatry 2019;41:556-67.

12 World Health Organization. COVID-19 in Malaysia situation report 10 2020. Available: file:///C:/Users/User/Downloads/malaysia-situationreport-10.pdf [Accessed 23 Oct 2020].

13 Hawthorne G, Herrman H, Murphy B. Interpreting the WHOQOLbrèf: preliminary population norms and effect sizes. Soc Indic Res 2006;77:37-59.

14 Wong JGWS, Cheung EPT, Cheung V, et al. Psychological responses to the SARS outbreak in healthcare students in Hong Kong. Med Teach 2004;26:657-66.

15 Loh L-C, Ali AM, Ang T-H, et al. Impact of a spreading epidemic on medical students. Malays J Med Sci 2006;13:30-6.

16 Wong TW, Gao Y, Tam WWS. Anxiety among university students during the SARS epidemic in Hong Kong. Stress and Health 2007;23:31-5.

17 Jeong H, Yim HW, Song Y-J, et al. Mental health status of people isolated due to middle East respiratory syndrome. Epidemiol Health 2016;38::e2016048.

18 Preti E, Di Mattei V, Perego G, et al. The psychological impact of epidemic and pandemic outbreaks on healthcare workers: rapid review of the evidence. Curr Psychiatry Rep 2020;22:43.

19 Lovibond SH, Lovibond PF. Manual for the depression anxiety stress scales. Sydney, NSW, Australia: Psychology Foundation of Australia, 1995.

20 Musa R, Fadzil MA, Translation ZZ. Validation and psychometric properties of bahasa Malaysia version of the depression anxiety and stress scales (DASS). ASEAN J Psychiatr 2007;8:82-9 https:// www.researchgate.net/publication/238675002 Validation and Psychometric_Properties_of_Bahasa_Malaysia_Version_of_the Depression_Anxiety_And_Stress_Scales_DASS_Among_Diabetic_ Patients

21 Zimet GD, Dahlem NW, Zimet SG, et al. The multidimensional scale of perceived social support. J Pers Assess 1988;52:30-41.

$22 \mathrm{Ng} \mathrm{CG}$, Amer Siddiq AN, Aida SA, et al. Validation of the Malay version of the multidimensional scale of perceived social support (MSPSS-M) among a group of medical students in faculty of medicine, University Malaya. Asian J Psychiatr 2010;3:3-6.

23 The WHOQOL Group. Development of the world health organization WHOQOL-bref quality of life assessment. The WHOQOL group. Psychol Med 1998;28:551-8.

24 Hasanah Cl, Naing L, Rahman AR. World Health organization quality of life assessment: brief version in Bahasa Malaysia. Med J Malaysia 2003;58:79-88.

25 El Ansari W, Stock C. Is the health and wellbeing of university students associated with their academic performance? cross sectional findings from the United Kingdom. Int J Environ Res Public Health 2010;7:509-27.
26 Allison MA, Attisha E, COUNCIL ON SCHOOL HEALTH. The link between school attendance and good health. Pediatrics 2019;143:e20183648.

27 Walen HR, Lachman ME. Social support and strain from partner, family, and friends: costs and benefits for men and women in adulthood. J Soc Pers Relat 2000;17:5-30.

28 Morrissey JL, Janz KF, Letuchy EM, et al. The effect of family and friend support on physical activity through adolescence: a longitudinal study. Int J Behav Nutr Phys Act 2015;12:103.

29 Lindsay Smith G, Banting L, Eime R, et al. The association between social support and physical activity in older adults: a systematic review. Int J Behav Nutr Phys Act 2017:14:56.

30 Sharma D, Bhaskar S. Addressing the Covid-19 burden on medical education and training: the role of telemedicine and teleeducation during and beyond the pandemic. Front Public Health 2020;8:589669

31 Ribeiro Ícaro J.S., Pereira R, Freire IV, et al. Stress and quality of life among university students: a systematic literature review. Health Prof Educ 2018;4:70-7.

32 Cai W, Lian B, Song X, et al. A cross-sectional study on mental health among health care workers during the outbreak of corona virus disease 2019. Asian J Psychiatr 2020;51:10211.

$33 \mathrm{Li}$ Y, Peng J. Coping strategies as predictors of anxiety: exploring positive experience of Chinese university in health education in COVID-19 pandemic. Creat Educ 2020;11:735-50.

34 Liu Q, Luo D, Haase JE, et al. The experiences of health-care providers during the COVID-19 crisis in China: a qualitative study. Lancet Glob Health 2020;8:e790-8.

35 Xiao H, Zhang Y, Kong D, et al. The effects of social support on sleep quality of medical staff treating patients with coronavirus disease 2019 (COVID-19) in January and February 2020 in China. Med Sci Monit 2020;26:e923549-1-e923549-8.

36 Song X, Fu W, Liu X, et al. Mental health status of medical staff in emergency departments during the coronavirus disease 2019 epidemic in China. Brain Behav Immun 2020;88:60-5.

37 Nguyen AW, Chatters LM, Taylor RJ, et al. Social support from family and friends and subjective well-being of older African Americans. $J$ Happiness Stud 2016;17:959-79.

38 Mcllvane JM, Reinhardt JP. Interactive effect of support from family and friends in visually impaired elders. $J$ Gerontol B Psychol Sci Soc Sci 2001;56:374-82.

39 Guo J, Feng XL, Wang XH, et al. Coping with COVID-19: exposure to covid-19 and negative impact on livelihood predict elevated mental health problems in Chinese adults. Int J Environ Res Public Health 2020;17:3857.

40 Berlim MT, Fleck MP. Quality of life impairment in schizophrenia, mood and anxiety disorders. In: Ritsner MS, Awad AG, eds. Quality of life and major depression. Dordrecht: Springer, 2007: 241-52.

41 Shumye S, Belayneh Z, Mengistu N. Health related quality of life and its correlates among people with depression attending outpatient department in Ethiopia: a cross sectional study. Health Qual Life Outcomes 2019;17:169.

42 Brewer G, Robinson S, Sumra A, et al. The influence of religious coping and religious social support on health behaviour, health status and health attitudes in a British Christian sample. J Relig Health 2015;54:2225-34.

43 Daily S. Religion or spirituality has positive impact on romantic/ marital relationships, child development, research shows, 2014. Available: https://www.sciencedaily.com/releases/2014/12/ 141208105320.htm [Accessed 18 Oct 2020].

44 Zhang Y, Ma ZF. Impact of the COVID-19 pandemic on mental health and quality of life among local residents in Liaoning Province, China: a cross-sectional study. Int J Environ Res Public Health 2020;17:2381.

45 Gardner TM, Krägeloh CU, Henning MA. Religious coping, stress, and quality of life of muslim university students in New Zealand. Ment Health Relig Cult 2014;17:327-38.

46 Vitorino LM, Lucchetti G, Santos AEO, et al. Spiritual religious coping is associated with quality of life in institutionalized older adults. $J$ Relig Health 2016;55:549-59.

47 National research council (US) panel on understanding divergent trends in longevity in highincome countries. explaining divergent levels of longevity in high-income countries, 2011. National academies press (US). Available: https://www.ncbi.nlm.nih.gov/books/NBK62364/

48 Barrable A. Papadatou-Pastou M, Tzotzoli P. Supporting mental health, wellbeing and study skills in higher education: an online intervention system. Int J Ment Health Syst 2018;12:54.

49 El Said GR. How did the COVID-19 pandemic affect higher education learning experience? an empirical investigation of learners' academic performance at a university in a developing country. Advan HumComp Interaction 2021;2021:1-10. 
50 Gopal R, Singh V, Aggarwal A. Impact of online classes on the satisfaction and performance of students during the pandemic period of COVID 19. Educ Inf Technol 2021:1-25.

51 Moussa NM, Ali WF. Exploring the relationship between students academic success and happiness levels in the higher education settings during the lockdown period of COVID-19. Psychol Rep 2021:33294121994568.
52 Hirschmann R. Number of international students in higher education in Malaysia 2019, by country, 2020. Available: https://www.statista. com/statistics/866731/international-students-in-malaysia-bycountry-of-origin/ [Accessed Access 20 May 2021].

53 Bhaskar S, Rastogi A, Menon KV, et al. Call for action to address equity and justice divide during COVID-19. Front Psychiatry 2020;11:559905. 